\title{
Long Range Ordered (LRO) Superalloys
}

\author{
K. R. Finney and L. W. Lherbier \\ Universal-Cyclops Specialty Steel Division \\ Mayer Street \\ Bridgeville, PA I5017
}

\begin{abstract}
Summary
The feasibility of producing an intermetallic alloy with a long range ordered (LRO) structure via powder metallurgy technology was demonstrated and the subsequent product evaluated for mechanical properties. A cobalt based alloy in the (CoFe) $3 \mathrm{~V}$ system was used in the study. Product was successfully produced by consolidating gas atomized powder via the CAPR process, extruding, and hot rolling to size. Heat treatment and subsequent testing showed superior high temperature strength and good ductility as measured by tensile and stress rupture tests. Structural characteristics were examined by light microscopy, SEM and X-ray diffraction. These results confirmed the presence of a long range ordered cubic structure and a uniform segregation free microstructure. Producing an intermetallic alloy of this type via powder metallurgy techniques with its advantages of composition and structural control suggests that it may be the optimum process for manufacturing alloys of this type.
\end{abstract}




\section{Introduction}

Designers of components for use in the gas turbine industry continually desire materials with improved high temperature strength. The benefits have been well documented. The degree of difficulty encountered in obtaining higher strength at higher temperatures is aptly demonstrated by longevity of usage for some materials. Two of the best known are Alloy HX and Alloy 188, two of the most popular nickel and cobalt base alloys, respectively. The former was developed in the 1950's while the latter was introduced in the 1960's. Together they represent most of the volume currently used in gas turbine applications involving combustion chambers and liners, after burner liners, nozzles, baffles, flame holders, etc. These materials are austenitic solid solution hardened alloys that demonstrate good high temperature strength and thermal stability along with other attributes required for these applications.

The long time use of Alloy HX and Alloy 188 demonstrates the difficulty of developing new thermally stable materials with even higher strength. Metallurgical theory has long suggested that high strength can be obtained with intermetallic alloys that exhibit a long range ordered (LRO) structure. Such a structure is illustrated in Figure 1 and essentially shows a fixed position of atoms in each and every unit cell. The difficulty with intermetallics has always been low ductility, akin to the problem with ceramics. However, work in the 1970's at Oak Ridge National Laboratory has demonstrated the feasibility of developing on a laboratory basis intermetallic alloys with LRO structures and adequate ductility for use in high temperature applications(1). Evaluation of several intermetallic LRO alloys containing the major alloying elements cobalt, nickel, iron and vanadium demonstrates control of a disorder-order reaction by heat treatment can significantly increase strength, creep and fatigue properties of elevated temperatures.

Principal requirements for LRO alloys include composition control (to insure the ordered reaction and reduce grain boundary brittleness) and structural uniformity to prevent the harmful effects of segregation on ordering. In analyzing the potential development of such materials to commercial reality it becomes apparent that the inherent aforementioned requirements of LRO alloys may be best served by powder metallurgy manufacturing techniques. A program was initiated to determine the feasibility of producing an intermetallic LRO alloy by the latest powder metallurgy technology involving rapid solidification techniques, consolidation by the CAP process and thermomechanical working. This paper discusses the processing of the alloy and its structural and property evaluation.

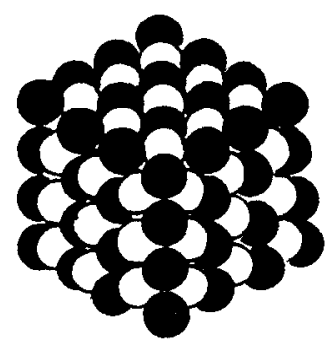

(a)

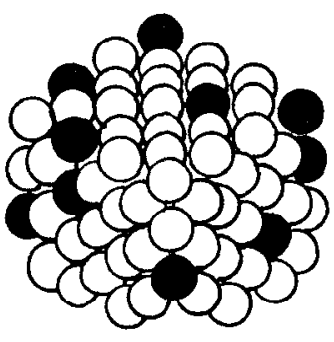

(b)

Figure I: Example of ordered (a) and disordered (b) crystal structures. 


\section{Procedure}

\section{Alloy Selection}

Long range order has been observed in many alloy systems. A correlation has been observed between the atomic stacking sequence and the electron concentration which is defined as the average per atom of the number of electrons outside the inert gas shells of an atom. As the electron concentration increases the stacking order changes from all cubic (example $\mathrm{Cu}_{3} \mathrm{Au}$ ) through different types of ordered mixtures to all hexagonal (example $\mathrm{Ni}_{3} \mathrm{Sn}$ ). 2

While the crystallography of order structures had been extensively studied it was not until the 1970's that work was conducted on the kinetic aspects of atomic ordering and structural transformations. Results showed that intermetallic alloys in the $\mathrm{V}-\mathrm{Co}-\mathrm{Ni}-\mathrm{Fe}$ system could upon isothermal aging yield first the formation of a cubic ordered structure from the face centered cubic matrix and with time the subsequent transformation to a stable ordered phase with hexagonal symmetry. (1)

While the metastable cubic ordered structure was very ductile at room temperature, material with the hexagonal structure was extremely brittle. It was concluded that the brittle nature exhibited by this material was not directly related to atomic ordering but to the cubic to hexagonal transformation. Further work demonstrated that ductility could be maintained in these materials by controlling the ordered structure.(2) If cobalt is partially replaced with iron and nickel in the base composition $\mathrm{Co}_{3} \mathrm{~V}$, the electron density $(\mathrm{e} / \mathrm{a})$ in the alloy can be adjusted to stabilize the cubic ordered structure. Figure 2 illustrates the principal involved, listing composition limits along with the e/a ratio needed to maintain a stable crystal structure.

Since an intermetallic alloy with good high temperature strength and poor ductility is of little practical value, the alloy selected for this study was based on choosing a composition that would theoretically maintain a stable cubic ordered structure after isothermal aging. Similarly it was desired that the critical temperature ( $T_{C}$-annealing temperature at which the ordered structure becomes disordered) would be as high as possible. The resultant composition therefore consisted of appropriate amounts of cobalt, iron and vanadium to form the intermetallic alloy $(\mathrm{CoFe})_{3} \mathrm{~V}$. The aim and actual composition of the heat KR 717 , identified as alloy LRO26 is listed in Table I.

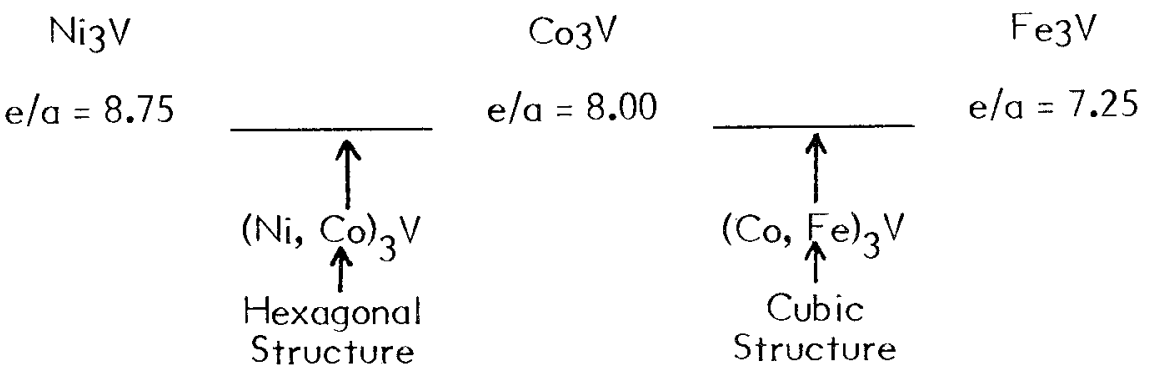

Figure 2: Effect of electron density (e/a) on crystal structure of ( $\mathrm{Ni}, \mathrm{Co}, \mathrm{Fe})_{3} \mathrm{~V}$ alloys ${ }^{2}$ 
Table I. Chemical Analysis of LRO26

\begin{tabular}{|c|c|c|c|c|c|c|c|c|c|}
\hline \multirow{2}{*}{$\begin{array}{l}\text { Heat } \\
\text { No. }\end{array}$} & \multicolumn{9}{|c|}{ Element (N+. \%) } \\
\hline & $\mathrm{C}$ & $\mathrm{Si}$ & $\mathrm{Co}$ & $\mathrm{Fe}$ & $\mathrm{V}$ & $\overline{\mathrm{Al}}$ & $\mathrm{Ti}$ & $\mathrm{O}$ & $N$ \\
\hline KR 717 & 0.016 & 0.76 & Bal. & 16.44 & 20.95 & 0.32 & 0.38 & 140 ppm & 150 ppm \\
\hline Aim & 0.04 & $\frac{0.05}{0.15}$ & Bal. & $\frac{16.0}{16.5}$ & $\frac{21.0}{22.0}$ & $\frac{0.45}{0.50}$ & $\frac{0.35}{0.45}$ & Low & Low \\
\hline
\end{tabular}

Material

The material used in this study was initially prepared by vacuum melting and subsequently to powder by argon gas atomization. Melting was conducted in a 200 pound vacuum induction furnace using commercially available raw materials. The principal materials included electrolytic cobalt and iron and ferro-vanadium. Atomization parameters were adjusted to produce a pour rate of approximately 50 pounds per minute. The powder was collected in a bed fluidized with argon and achieved a calculated cooling rate in excess of $10^{\circ} \mathrm{C}$ per second. The resultant powder was screened to -100 mesh inclusive to remove any flash or oversized particles and blended to achieve a homogeneous particle size distribution. As noted in Table l, the material met the desired chemical analysis for the major elements. Residual elements contained in LRO26 are also noted.

Powder preforms were prepared using the CAP (consolidation by atmospheric pressure) process, which involves the consolidation of powder via sintering in a borosilicate container. An outline of the process is illustrated in Figure 3 and involves loading the blended powder into a shaped container, evacuating, sealing and sintering at a temperature and time determined by the alloy and the mass being consolidated. Vacuum levels during degassing reached $5 \times 10-6$ torr. Sealing of the preforms was accomplished when a leak rate of 0.3 microns per second was achieved. During the sintering operation the glass container softens and the resultant atmosphere to vacuum pressure differential causes the container to be deformed inward. Consolidation occurs as a result of powder particle diffusion producing a shape consistent with the original borosilicate mold and desired density. Preliminary consolidation trials were conducted on 1-1/4" diameter molds using temperatures ranging from 2200 to $2400^{\circ} \mathrm{F}\left(1204-1315^{\circ} \mathrm{C}\right)$ and times up to 24 hours. Establishment of the appropriate consolidation parameters for LRO26 were then used to produce two and three inch diameter preforms for subsequent fabrication and evaluation.

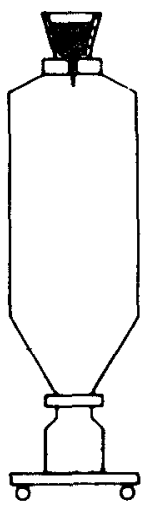

Atomize
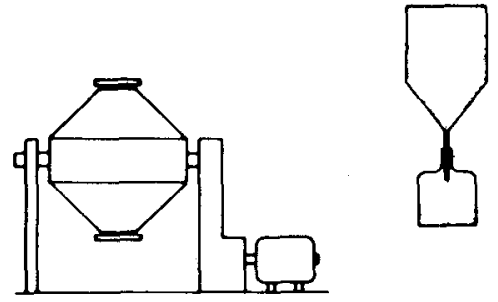

Blend

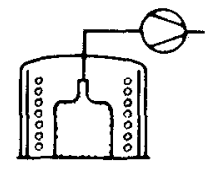

Load Degas

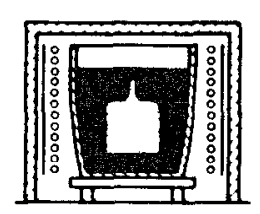

Sinter

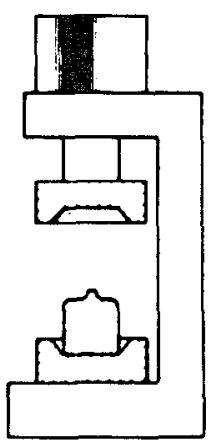

Hot Work

Figure 3: Outline of P/M CAP Consolidation Process 
Final densification of $P / M$ CAP preforms can be achieved via hot working operations or by hot isostatic pressing. In this program, preforms were consolidated to fully dense product by hot rolling and by extrusion. Two inch diameter preforms of LRO26 were consolidated, conditioned and subsequently rolled to 1/2" diameter bar on a laboratory rolling mill. The preforms were charged into a furnace and heated to the rolling temperature of $1950^{\circ} \mathrm{F}\left(1065^{\circ} \mathrm{C}\right)$, held I hour and subsequently rolled to finish size. The actual rolling operation required a number of reheats to reach the finish size noted. An assessment of hot workability was based on surface inspection of the rolled bar.

Three inch diameter preforms of LRO26 were prepared for the extrusion trials at TRW. The preforms, after surface conditioning, were canned into 1/2" wall mild steel tubing and fitted with nose and tail plates. A ceramic compound coating was applied to the canned preforms prior to extrusion to provide lubrication and oxidation protection. Extrusion trials were conducted at 1900 and $2000^{\circ} \mathrm{F}\left(1038-1093^{\circ} \mathrm{C}\right)$. Temperatures were maintained within plus or minus $5^{\circ} \mathrm{F}$ of the specified temperature. Once at temperature, the preforms were held for 90 minutes and extruded utilizing both a preheated $700^{\circ} \mathrm{F}\left(371^{\circ} \mathrm{C}\right)$ die and liner. All bars were covered with sand immediately after extrusion, held for aproximately 15 minutes and subsequently air cooled. Removal of the can showed an approximate extruded diameter for the LRO26 alloy of 0.70 inches. The calculated extrusion ratio was 9.8 to 1 .

Heat Treatment and Structure

The heat treatment cycle for materials of the LRO26 type had been established from previous work. I That heat treatment, which involves solution treating at $2012^{\circ} \mathrm{F}\left(1100^{\circ} \mathrm{C}\right)$ for 1 hour, water quenching, followed by a two-step aging treatment at $1472^{\circ} \mathrm{F}\left(800^{\circ} \mathrm{C}\right)$ for 5 hours, furnace cooling to $1300^{\circ} \mathrm{F}\left(704^{\circ} \mathrm{C}\right)$, holding 24 hours and water quenching was applied to all material in this study. The purpose of the solution treatment is to produce an austenitic disordered face centered cubic ( $\mathrm{fcc}$ ) structure which is maintained at room temperature by the water quench. The aging treatment results in an ordered structure that maintains its stability until it reaches a critical temperature $\left(T_{C}\right)$ at which point the structure reverts back to a disordered state.

Initial structural studies consisted of light microscopy on consolidated asCAPed material and on solution treated and solution treated and aged material which had been fabricated to full density. Structures were examined on a B\&L Research II Metallograph at magnifications ranging from 100 to $1000 \times$. Sample preparation involved normal procedures with all structures being etched in a solution of 50/50 $\mathrm{HCl}$. Scanning electron microscope (SEM) studies were conducted on the fractured surfaces of tensile and stress rupture specimens. All SEM work was conducted on solution treated and aged samples utilizing a JEOL JSM-U3 unit equipped with an EDAX analyzer and PGT detector.

Material in the as-rolled solution treated and solution treated and aged conditions was subjected to $x$-ray diffraction analysis to verify the disorder/order reaction predicted for the LRO26 composition. The work was conducted on a GE XRD5 utilizing a $0.2^{\circ}$ detector slit with a scanning speed of $0.2^{\circ}$ per minute. A chromium large target tube was employed. Specimen preparation involved grinding all surfaces to -320 grit and subsequently determining $d$-spacing via linear regression plotting of chart peaks on a HP85 mini computer.

Testing

Standard tensile and stress rupture test bars with a 0.160 gage diameter and a 1.0 inch gage length were heat treated and machined using low stress grinding 
procedures. Room temperature tensile tests were conducted on solution treated and solution treated and aged material. Elevated temperature tensile tests were conducted at temperatures ranging from $1000^{\circ} \mathrm{F}$ to $1700^{\circ} \mathrm{F}\left(538-927^{\circ} \mathrm{C}\right)$ on solution treated and aged material. All tensile tests employed a $0.005 \mathrm{in.} / \mathrm{in.} / \mathrm{sec}$. strain rate to the yield point and a strain rate of $.05 \mathrm{in.} / \mathrm{in} . / \mathrm{sec}$. thereafter. Hold time at temperature prior to tensile testing was 25 minutes. A series of stress rupture tests were conducted on solution treated and aged material at temperatures ranging from 1300 to $1700^{\circ} \mathrm{F}\left(704-927^{\circ} \mathrm{C}\right)$. Stress levels ranged from a high of 70,000 psi at $1300^{\circ} \mathrm{F}$ $\left(704^{\circ} \mathrm{C}\right)$ to a low of 5,000 psi at $1700^{\circ} \mathrm{F}\left(927^{\circ} \mathrm{C}\right)$. Hardness tests were conducted on solution treated and solution treated and aged material as well as on test specimens after completion of testing.

$\underline{\text { Results }}$

\section{Material Processing}

Preliminary consolidation trials on the LRO26 employed sintering temperatures from 2200 to $2400^{\circ} \mathrm{F}\left(1204-1315^{\circ} \mathrm{C}\right)$ with times up to 24 hours. Satisfactory density (greater than $96 \%$ ) was achieved with sintering temperatures of 2250 and $2300^{\circ} \mathrm{F}$ $\left(1232-1260^{\circ} \mathrm{C}\right)$. Time of sintering varied with preform size. Sintering at $2300^{\circ} \mathrm{F}$ yielded a density of $98.4 \%$ while $2250^{\circ} \mathrm{F}\left(1232^{\circ} \mathrm{C}\right)$ resulted in a density of $97.4 \%$. Grain size for these densities were ASTM 3 to 5, respectively. Sintering temperatures lower than $2250^{\circ} \mathrm{F}\left(1232^{\circ} \mathrm{C}\right)$ gave low densities while temperatures higher than $2300^{\circ} \mathrm{F}\left(1260^{\circ} \mathrm{C}\right)$ produced coarse grains and/or liquation. Sintering temperatures in the 2250 to $2300^{\circ} \mathrm{F}\left(1232-1260^{\circ} \mathrm{C}\right)$ were chosen for consolidation of larger preforms that were subsequently hot worked to fully dense product.

Hot rolling of LRO26 preforms from a temperature of $1950^{\circ} \mathrm{F}\left(1065^{\circ} \mathrm{C}\right)$ was accomplished without dificulty. The material was subjected to as many as 8 passes between reheats. A number of reheats was needed to reach the final bar size of $1 / 2^{\prime \prime}$ round. Inspection of the surface showed a smooth appearance with no cracks. Hot workability was judged to be excellent. LRO26 preforms were also successfully extruded at a ratio of 9.8 to I from both 2000 and $1900^{\circ} \mathrm{F}\left(1093\right.$ and $\left.1038^{\circ} \mathrm{C}\right)$. Breakthrough and running pressure varied as expected with temperature. The extruded bar measured 0.70 inches in diameter and exhibited a smooth crack free surface.

\section{Microstructure}

Initial microstructural examination was conducted on as-hot worked material and showed a fully dense recrystallized structure with a relatively fine grain size of ASTM 8. Examination of solution treated $2012^{\circ} \mathrm{F}\left(1100^{\circ} \mathrm{C}\right) / / \mathrm{hr} / \mathrm{WQ}$ material also showed a fully recrystallized austenitic structure with a grain size of ASTM 6 . The structure of aged $\left[1472^{\circ} \mathrm{F}\left(800^{\circ} \mathrm{C}\right) / 5 \mathrm{hrs} / \mathrm{FC}\right.$ to $\left.1300^{\circ} \mathrm{F}\left(704^{\circ} \mathrm{C}\right) / 24 \mathrm{hrs} / \mathrm{WQ}\right]$ material showed a fine precipitate at the grain boundaries and fewer visible annealing twins. Both the solution treated and solution treated and aged optical structures are illustrated in Figure 4. Subsequent SEM analysis of the fine precipitate as illustrated in Figure 5 shows the presence of titanium, presumably present in the form of a carbide.

$X$-ray diffraction analysis of the solution treated material resulted in a calculated $d$-spacing which confirmed the presence of a cubic structure in this condition. Further $X$-ray work on solution treated and aged material showed a decrease in $d$-spacing as determined by regression analysis and the presence of superlattice lines $[(110),(2 / 0)]$, thus supporting the disorder-order transformation predicted for the LRO26 alloy. The reduction in d-spacing from 3.579 to $3.574 \AA$ results in a difference that coincides with values previously reported. (1) 


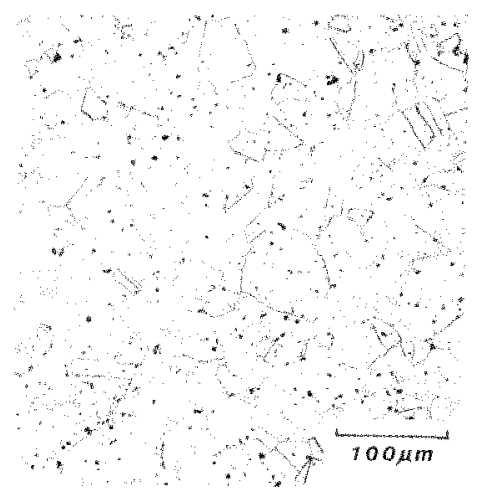

Figure 4

Solution treated (a) and solution treated plus aged (b) structures

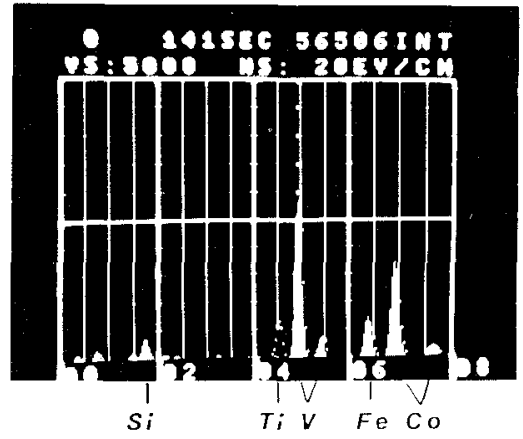

Figure 5

Major elements in matrix (bars) and GB precipitate (dots)

\section{Mechanical Properties}

Room temperature tensile tests were conducted on solution treated and solution treated and aged material. These results, along with the results of elevated temperature tensile tests on fully heat treated material are listed in Table $I I$ and illustrated in Figure 6. Solution treated material shows a wide spread between ultimate and yield strengths with very good ductility. Similar room temperature strength levels are observed for fully heat treated material with only slightly lower ductility. The results confirm the presence of the cubic structure as opposed to a brittle close packed hexagonal structure observed in many intermetallic alloys. Hardness showed no significant difference between solution treated and full heat treated material, varying between 58 and 60 RA.

Elevated temperature tensile tests show a steady decline of ultimate strength with increasing temperature up to $1600^{\circ} \mathrm{F}\left(871^{\circ} \mathrm{C}\right)$ after which a precipitous drop is observed. The critical temperature $\left(T_{C}\right)$ is reached and the order-disorder reaction apparently takes place. The yield strength, however, increases with increasing temperature reaching a maximum at $1500^{\circ} \mathrm{F}\left(815^{\circ} \mathrm{C}\right)$. This observation differentiates the LRO26 alloy from conventional polycrystalline materials and demonstrates the advantage of an ordered structure at elevated temperatures. While ductility does decline at elevated temperatures when compared to room femperature values, it does maintain quite acceptable levels.

Table 1I. Effect of Temperature on the Tensile Properties of LRO26

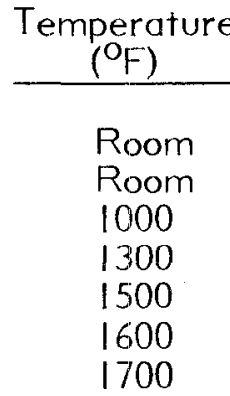

Ultimate Condition

\section{Sol. Treated}

Sol. Treated + Age

Sol. Treated + Age

Sol. Treated + Age

Sol. Treated + Age

Sol. Treated + Age

Sol. Treated + Age

\begin{tabular}{c} 
(psi) \\
\hline 184,600 \\
194,600 \\
163,600 \\
99,800 \\
82,300 \\
79,700 \\
17,700
\end{tabular}
$0.2 \%$ Yield (psi)

54,000

48,200

51,700

60,100

69,400

63,200

10,800
Elong.

(\%)

42.7

37.8

49.1

38.5

9.1

10.9

97.1
Reduction in Area (\%)

52.0

34.8

40.6

37.1

12.9

13.2

97.5 


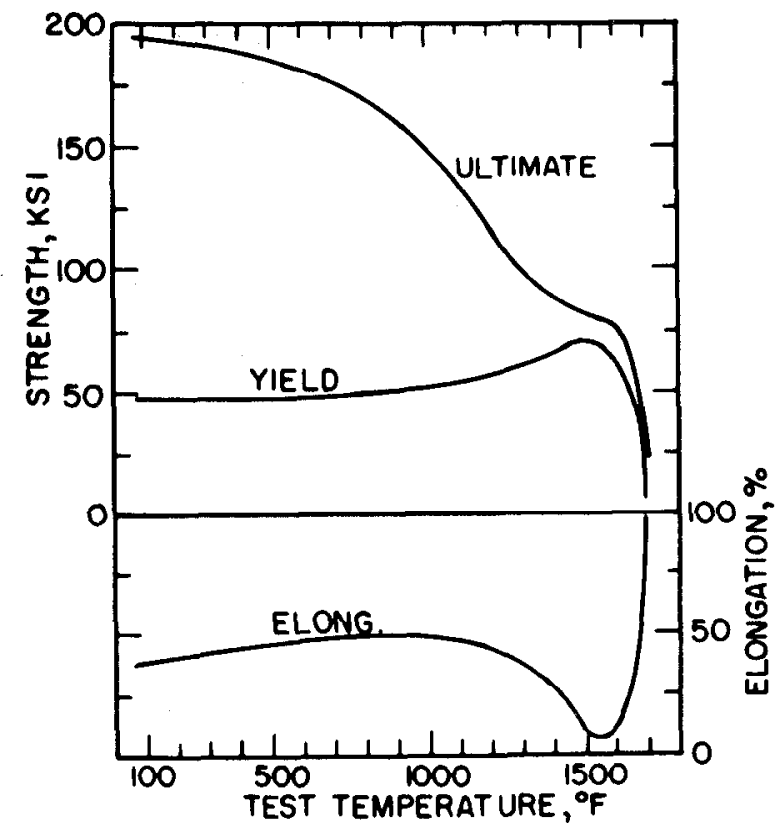

Figure 6

Effect of temperature on

tensile properties

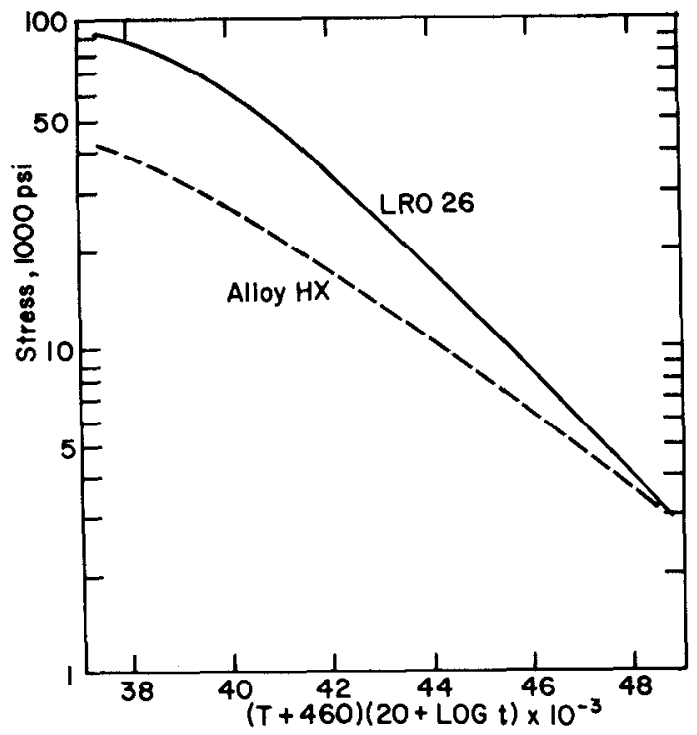

Figure 7

Rupture properties of $\mathrm{HX}$ and LRO26

Examination of the fracture modes exhibited by tensile test specimens clearly shows that fracture initiates and propagates along grain boundaries. SEM photographs of fractures at room temperature are illustrated in Figure 8. Despite the presence of good ductility, the absence of a dimpled surface is quite noticeable. The smooth surfaces of the grains stand out quite vividly. The elevated temperature fractures show a trend toward a dimpled fracture while still showing the smooth grain boundary fracture.

The results of a series of stress rupture tests are listed in Table III and illustrated on a Larson Miller parameter plot in Figure 7. The results show excellent strength over the temperature range from $1300^{\circ} \mathrm{F}$ to $1600^{\circ} \mathrm{F}\left(704^{\circ} \mathrm{C}\right.$ to $\left.87 I^{\circ} \mathrm{C}\right)$ with good ductility. Rupture strength drops off dramatically once the critical temperature $\left(T_{C}\right)$ is surpassed. The effect of the ordered structure on this intermetallic alloy is clearly evident. SEM examination of fractures for temperatures up to $1600^{\circ} \mathrm{F}\left(871^{\circ} \mathrm{C}\right)$ again closely follow grain boundaries. However, the fracture mode of rupture specimens tesied at $1700^{\circ} \mathrm{F}\left(927^{\circ} \mathrm{C}\right)$ and above $\mathrm{T}_{\mathrm{C}}$ shows a dramatic change in appearance. Rupture strength decreases dramatically, ductility increases significantly and the fracture shows a bimodal appearance. Parts exhibit a classic ductile dimpled appearance while other parts of the fracture show grain boundary crack propagation on smooth faced grains. One also notes optically a mixed grain size ASTM 6 (as heat treated) with what appears to be dynamically recrystallized grains of ASTM 12. The stress applied during testing coupled with the high temperature which also is above the critical temperature $\left(T_{C}\right)$ apparently results in dynamic recrystallization. 
Table III, Stress Rupture Properties of LRO26

\begin{tabular}{|c|c|c|c|c|}
\hline $\begin{array}{c}\text { Temperature } \\
\left({ }^{\circ} \mathrm{F}\right) \\
\end{array}$ & $\begin{array}{c}\text { Stress } \\
\text { (psi) }\end{array}$ & $\begin{array}{l}\text { Life } \\
\text { (hrs) } \\
\end{array}$ & $\begin{array}{c}\text { Elongation } \\
(\%)\end{array}$ & $\begin{array}{c}\text { Reduction in } \\
\text { Area }(\%)\end{array}$ \\
\hline $\begin{array}{l}1300 \\
1300\end{array}$ & $\begin{array}{l}70,000 * \\
75,000 * *\end{array}$ & $\begin{array}{l}576.0 \\
298.4\end{array}$ & $\begin{array}{l}7.2 \\
5.7\end{array}$ & $\begin{array}{r}8.1 \\
14.3\end{array}$ \\
\hline $\begin{array}{l}1400 \\
1400\end{array}$ & $\begin{array}{l}50,000 \\
50,000\end{array}$ & $\begin{array}{l}73.5 \\
68.1\end{array}$ & $\begin{array}{l}6.9 \\
5.2\end{array}$ & $\begin{array}{l}9.1 \\
8.0\end{array}$ \\
\hline $\begin{array}{l}1500 \\
1500\end{array}$ & $\begin{array}{l}40,000 \\
40,000\end{array}$ & $\begin{array}{l}18.3 \\
16.7\end{array}$ & $\begin{array}{r}11.1 \\
9.7\end{array}$ & $\begin{array}{l}14.7 \\
15.5\end{array}$ \\
\hline $\begin{array}{l}1700 \\
1700\end{array}$ & $\begin{array}{l}5,000 \\
5,000\end{array}$ & $\begin{array}{r}44.6 \\
109.9\end{array}$ & $\begin{array}{l}92.9 \\
51.8\end{array}$ & $\begin{array}{l}97.2 \\
92.4\end{array}$ \\
\hline
\end{tabular}
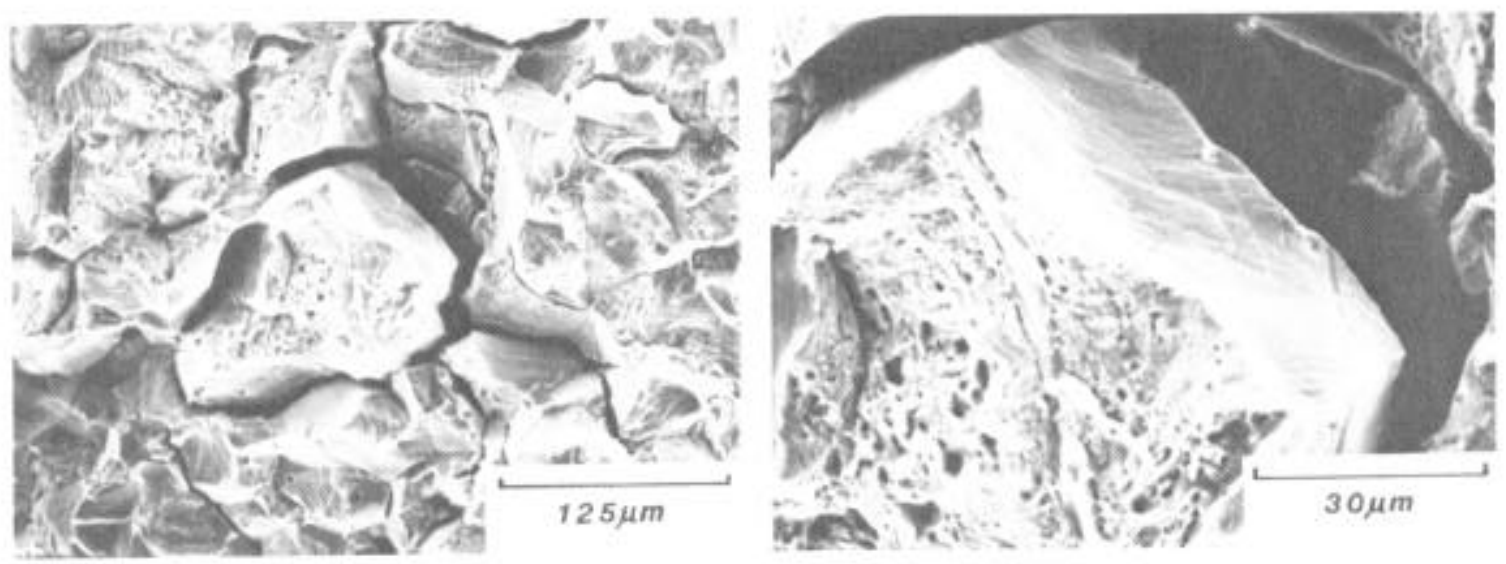

Figure 8: SEM Photo of LRO26 room temperature fractures

\section{$\underline{\text { Discussion }}$}

The feasibility of melting, atomizing to powder and consolidation of the LRO26 alloy to high density preforms presented no difficulty. Normal vacuum melting techniques were applied and only limited consolidation trials were necessary to achieve high density preforms. Fabrication by extrusion and hot rolling was accomplished with initially chosen hot working parameters. Ease of fabrication was attributed to the single phase fcc structure and high ductility.

Structural examination of the LRO26 material showed a uniform nonsegregated fully austenitic (fcc) matrix with what appears to be small dispersed carbides and inclusions. Beside the three major elements (Co, Fe, V) the material contained substantial amounts of aluminum, titanium and silicon along with normal residuals of carbon, oxygen and nitrogen. The aluminum and fitanium were intentional and aimed at keeping minor impurities out of the grain boundaries. The silicon was unintentional and the result of a high level in the ferro-vanadium. These additional elements may be responsible for the lower than anticipated critical temperature observed. More work on melt practice and residual elements appears warranted. 
The mechanical properties achieved with LRO26 met anticipated values. The strength and stability of the material was excellent from room temperature up to the critical $\left(T_{C}\right)$ temperature. Figure 8 shows the substantial advantage of LRO26 over Alloy $H X$ in respect to rupture strength. Other work on this family of alloys indicates superior creep and fatigue properties over the sume Alloy HX. While no oxidation testing was conducted, it was observed that the LRO26 alloy exhibited very severe scaling and spalling during elevated temperature testing. Any consideration of use in gas turbines would by necessity require a coating of some type. In looking at the total concept of intermetallic alloys, it would appear in retrospect that development work on $\mathrm{Ni} 3 \mathrm{Al}$ would be more fruitful. (3)

The work does, however, show the potential of intermetallic alloys for use at high temperature. They certainly represent a step up from currently used superalloys and a step closer to ceramics. Maintaining strength with ductility to higher temperatures, which appears feasible, would provide designers with new potential for gas turbine applications. However, significantly more development work is required if that potential is to be realized.

\section{Conclusions}

1) Advanced powder metallurgy technology is applicable to the manufacture of intermetallic alloys such as LRO26 (CoFe) $3 \mathrm{~V}$. The material can be produced as powder, consolidated and hot worked with commercial industrial practices.

2) The (CoFe) $3 \mathrm{~V}$ composition exhibited a stable cubic ordered structure as predicted by the electron density $(\mathrm{e} / \mathrm{a})$ ratio theory from room temperature to approximately $1650^{\circ} \mathrm{F}\left(900^{\circ} \mathrm{C}\right)$.

3) The LRO26 alloy demonstrated mechanical properties and structures consistent with those expected of ordered structures including good ductility and increasing yield strength with increasing temperature up to the critical temperature.

4) The demonstrated feasibility of producing intermetallic alloys with current manufacturing procedures coupled with the potential strength of these materials at elevated temperatures indicates the need for further development of these materials.

\section{References}

1. C. T. Liu and H. Inouye, "Control of Ordered Structure and Ductility of (Fe, Co, Ni) 3 V Alloys", Metallurgical Transactions A, 10A (10) (1979) pp. 1515-1525.

2. Internal publication ORNL-DWG 80-92IIR, C. T. Liu, Oak Ridge National Laboratory, rec'd Oct. 1982.

3. C. T. Liu and C. C. Koch "Development of Ductile Polycrystalline Ni3Al for High Temperature Applications" Technical Aspects of Critical Materials Use by the Steel Industry, Vol. IIB (10) (1982) pp. $1-19$. 